\title{
Photonics Xplorers and Leaders: challenging diverse students in a flat world for emerging careers
}

Joyce Hilliard-Clark, Pamela Gilchrist

Joyce Hilliard-Clark, Pamela O. Gilchrist, "Photonics Xplorers and Leaders: challenging diverse students in a flat world for emerging careers," Proc. SPIE 9665, Tenth International Topical Meeting on Education and Training in Optics and Photonics, 96650F (3 June 2007); doi: 10.1117/12.2207486

SPIE Event: Tenth International Topical Meeting on Education and Training in Optics and Photonics, 2007, Ottawa, Ontario, Canada 


\title{
Photonics Xplorers and Leaders: Challenging Diverse Students in a Flat World for Emerging Careers
}

\author{
Joyce Hilliard-Clark, Ph.D. and Pamela O. Gilchrist M.Ed \\ North Carolina State University The Science House. Imhotep Academy, Box 8211, Raleigh, NC 27856-8211 USA, 919 515-5570,

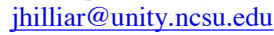 \\ North Carolina State University The Science House. Imhotep Academy, Box 8211, Raleigh, NC 27856-8211 USA, 919 513-7521, \\ pamela_gilchrist@.ncsu.edu
}

\begin{abstract}
The Photonics programs address the question of how to integrate scientific content, student encouragement, and parental support to engage minority high school students to experience success in areas of a national need. Historical data indicates African Americans do not take advanced mathematics and science courses, especially physics, in high school. Therefore, we propose using a variety of strategies for providing instruction in leadership, experimentation, research writing, communications and scientific presentation to work with students, families and teachers in promoting selection of and academic achievement in challenging science courses. Seventy-five African American students are participating in year-round Photonics programs at The Science House on NC State University's Centennial Campus. Students from sixteen counties in North Carolina learn about fiber optics, communications and the properties of light.
\end{abstract}

\section{Introduction}

The Piedmont Region of North Carolina is one of the fastest growing science and information technology centers of the world. Each day over 37,000 workers stream into Research Triangle Park where IBM, Nortel, Cisco and other science and technology companies operate major facilities. These technology, manufacturing and research facilities draw scientists and engineers from around the world, however there is a need for a larger and more diverse workforce, which should include more North Carolina natives. North Carolina must do more to attract and prepare students from diverse backgrounds to join the science and technology powerhouse this state has built.

The sixteen rural and urban counties served by Photonics Xplorers and Leaders include a population representative of the entire state, with about 31\% African American and 5\% Hispanic students. To underscore the need for the program, consider that for these counties the $9^{\text {th }}$ to $12^{\text {th }}$ grade student graduation rate of $42 \%$ to $65 \%$ brackets the statewide average. Of those that do graduate from high school about $48 \%$ go on to four-year colleges, and $34 \%$ to community colleges or technical schools. ${ }^{\text {il }}$ This college-going rate lags behind the national average.

A key step in the education of students for the science and technology workforce is the high school physics course, normally taken in the senior year in NC. While the national physics enrollment rate in the last decade has increased to about $28 \%^{2}$, in North Carolina in 2003-2004 only $10,555^{3}$ out of $356,000^{4}$ grade $9-12$ students took the high school physics end of course exam. This number has decreased slightly in the past decade. Although there is no statewide data on the relative participation of minorities in the high school physics course, nationally only about $22 \%$ of African Americans and Hispanics take physics. ${ }^{5}$ Obviously North Carolina needs to do more to promote and support minority students into science and technological careers.

While the percentages of African Americans and Hispanics in the national science and engineering workforce are steadily increasing, they are still below their relative representation in the college-degreed workforce. ${ }^{6}$ The national technology industry is lacking the contributions and strengths that come from a socially and ethnically diverse workforce. 
Origin of the Imhotep Academy, Photonics Xplorers and Photonics Leaders Program

Imhotep Academy is a pre-college program designed to increase student awareness and enthusiasm for learning science, technology and mathematics. Imhotep Academy is an integral part of The Science House, which is operated by the College of Physical and Mathematical Sciences at North Carolina State University. This robust program started over fifteen years ago for middle and high school students strives to improve students' grasp of science technology, engineering and mathematics (STEM). According to the Bureau of Labor Statistics, 20 of the 25 occupations listed as having the highest median annual earnings - including Anesthesiology, Computer and Information System Manager, Flight Engineers and Physicists - are dominated by the science fields. We want Imhotep children to fill these emerging positions. The main points of the Imhotep Academy business plan are:

- The mission of Imhotep Academy is to serve as a catalyst for change by teaching exciting hands-on inquiry-based lessons to enhance academic skills for underrepresented students in the disciplines of Mathematics, Marine, Earth and Atmospheric Sciences, Physics, Chemistry and Statistics, which are the departments in the College of Physical and Mathematical Sciences.

- The objective of Imhotep Academy is to nurture students' interest in pursuing science, math and technology careers.

- Imhotep Academy encourages underrepresented students to acquire and practice the skills required for success in the science, mathematics and technology workforce as identified by Thomas Friedman in The World is Flat.

- Imhotep Academy has expanded programming offerings to include the grant-funded high school component; Photonics Xplorers and Photonics Leaders.

- Imhotep Academy's success hinges upon serving a diverse population of motivated students, creative teachers and the supportive parents of students who return each session.

- Curriculum offerings include relevant theme-based instruction encouraging and stimulating academic interest and excitement for students and teachers.

- Evaluation data documents the continuous need for this student program in preparing females and underrepresented students for our high tech world.

- Imhotep Academy receives significant financial support from the College of Physical and Mathematical Sciences to tap into the talents of traditionally under-represented students.

- Future plans are to implement strategies for leveraging resources for growth and sustainability.

Imhotep Academy program meets a continuous need for nurturing and unleashing the potential of under-represented students to excel in mathematics, science and technology. Imhotep Academy's programs and other pre-college programs like it are more important than ever because public schools do not have the opportunity to expose and encourage children to fill the STEM type jobs that are available or emerging in our globally competitive world. Over the past decade, technological advancements have changed our lives and the job market. As a result, the National Science Foundation has predicted science and engineering careers in the United States will grow by 26 percent and that over half of the scientists and engineers are forty years or older. It is also predicted that by 2012 , we will have 1.25 million more positions in these fields. While the jobs grow, the people to fill them decrease and we must work to remedy the shortfall.

According to the National Science Foundation, African Americans represent only $6.9 \%$ of those employed in science and technology occupations in 2000. This is up from 20 years ago when it was $2.6 \%$, however, this rate is still below the proportion of African Americans in the population. Thus, these findings justify the need for this program's expansion and more resources for the educational pipeline to help turn this situation around. Imhotep Academy has expanded program offerings to include an algebra program and grant-funded high school component to further help students experience success in preparing for scientific classes and emerging careers.

The high school Photonics programs are preparing our next generation of technology leaders to be the catalyst of change by exposing students to new photonics related career options. Photonics Xplorers and Photonics Leaders are year round science, mathematics and technology programs for high school students from across North Carolina. Students attend these programs at The Science House on Centennial Campus at NC State University. For our success in the global economy, America depends upon a robust and reliable pipeline of scientists, technicians, technologists, engineers, and mathematicians. A recent ITEST newsletter stated that over $80 \%$ of the fastest growing 
occupations and two-thirds of the occupations with the largest job growth are dependent upon a knowledge base in mathematics and science. ${ }^{7}$ Fifty percent of the current engineering and science workforce are approaching retirement ${ }^{8}$ and U.S. universities will graduate qualified candidates to fill only $50 \%$ of the computer and information related jobs expected by $2012 .{ }^{9}$ Women and minorities still remain under-represented in the STEM workforce. A diverse American pipeline will increase our ability to create, innovate and adapt in the global market place.

From reading The World is Flat by Thomas Friedman, students in both programs (Photonics Xplorers and Photonics Leaders) explored emerging careers in the global market place and the implications as it impacted their lives and career preparation. From this reading the students and their families discovered the importance of a STEM education and the impact of photonics in every area of their life. The World is Flat provided a platform for students to grasp the importance of the field experience within the following companies: Progress Energy, Analytical Instrumentation Facility, NCSU; College of Veterinarian Medicine, NCSU; IBM, Friday Institute, NCSU; Merck Pharmaceutical, NCSU College of Engineering, NCSU; North Carolina Division of Water Quality, North Carolina Department of Natural Resources, Shoder Education Foundation, Cisco Systems, Inc. Instrotek, Inc, Jones Cnossen and Dolle Engineering; BD Technology, Plexus Technology, EMBARQ and the Physics Laboratory, NCSU. At the end of the summer experience, students were able to synthesize and integrate the importance of their experience into an oral presentation as well as written reports.

In 2007, the Photonics Xplorers program will complete three years of programming and Photonics Leaders will complete two years of engaging nearly 120 high school students in the wonders of photonics (the science of light energy), mathematics, scientific research and presentation skills, organizational, leadership, career preparation skills (resume, interview, communication). Our goal is to improve students' competence in science and nurture their interest in science, research and careers.

\section{Xplorers and all its features}

Photonics Xplorers is a multidisciplinary program for culturally diverse students that are historically underrepresented in the sciences and engineering. Photonics Xplorers is funded by the Burroughs Wellcome Fund (BWF) Student Science Enrichment Program Awards to support creative science enrichment activities for students in the sixth through twelfth grades who have shown exceptional skills and an interest in science, as well as those who may not have an opportunity to demonstrate conventional "giftedness" in science but are perceived to have high potential.

Photonics Xplorers, a year-round program for high school freshmen and sophomores funded by the Burroughs Wellcome Fund. The Xplorers have made the leap to high school and are learning strategies to succeed. They are building their mathematics skills and learning about light and communications using the nationally recognized Active Physics ${ }^{10}$ curriculum.

The Xplorers project is an outgrowth of Imhotep Academy, an academic year and summer enrichment program for middle school students from groups underrepresented in science and mathematics. In the past fifteen years the Academy has averaged 50 6-8 ${ }^{\text {th }}$ grade participants per semester totaling into the thousands students served. Many former Academy students are now college graduates and have testified to the importance of the Academy in guiding their career aspirations.

Photonics Xplorers introduces twenty ninth and tenth graders annually, mostly from groups underrepresented in science and engineering, to the technology of optical science and photonics. Two groups of twenty students recruited from nearby schools and from science enrichment programs for underserved students such as the Imhotep Academy participate in a two-year continuous learning and mentoring experience. In each session of the two-year program students investigate optics, electronics, build devices, learn about photonics careers, meet scientists, and present their findings to others, especially their peers and corporate partners. 
The students meet one week each summer and five Saturdays each academic semester. The students construct optical and electronic devices and perform experiments that teach physics science content, experimental skills and provide products for students to share with their teachers and fellow students. These activities build on the extensive expertise in optics and photoelectronics at NC State and in Research Triangle Park, as well as the excellent teaching laboratory facilities at The Science House. Drawing from the nearly fifteen-years experience of the Imhotep Academy in mentoring middle school students and their parents, we counsel the ninth and tenth graders, and their parents about course selection in mathematics, science, college preparation and career choices in high school. Upon successful completion of Photonics Xplorers, students are recruited to become Photonics Leaders.

The fundamental goal of the Photonics Xplorers project is to encourage students to take advanced mathematics and science courses all four years of their high school experience. To achieve this goal we

- provide hands-on experiences that build confidence and a sense of personal achievement in science,

- reinforce fundamental mathematics and science concepts that are central to high school science and mathematics courses,

- counsel and encourage students with mentors and role models in the science and engineering field

- channel the rising eleventh and twelfth grades students toward other science and mathematics enrichment programs such as Photonics Leaders.

The students are recruited from middle and high schools near the NC State campus and from programs that focus on middle school students from groups underrepresented in science and mathematics. These include the Imhotep Academy and SPACE program, Upward Bound and MSEN Precollege programs at NC State, UNC-CH, NC Central University and North Carolina.

We intend that each student will complete two full years with the program and will be prepared to participate in science enrichment activities targeted towards eleventh and twelfth graders. Building on their experiences from grade six through ten science enrichment programs at NC State, upon completion of the Photonics Leaders programs students will be prepared to step into existing collegiate research internships at NC State and elsewhere.

Photonics Xplorers consisted of 58 participants, 22 males (38\%) and $36(62 \%)$ females during the last 3 years with students from 15 different counties in North Carolina. Students were selected to produce a diverse cohort of students with the following ethnic backgrounds: 72\% African-American, 6\% Asian, 4\% Bi-racial, 14\% Caucasian and 4\% Hispanic. All the students accepted in the program had above a 3.00 grade point average.

\section{Leaders and all its features}

Photonics Leaders is funded by the National Science Foundation (NSF) Information Technology Experiences for Students and Teachers (ITEST) program established in direct response to the concern about shortages of IT workers in the United States. ITEST program funds projects that provide opportunities for both school-age children and teachers to build skills and knowledge needed to advance their study and to enable them to function and contribute in a technologically rich society.

In July 2005, the Photonics Leaders project was established at North Carolina State University with a grant from the National Science Foundation (NSF). In accordance with the goals of the ITEST program we seek "to provide opportunities for school-age children ... to build the skills and knowledge needed to advance their study, and to function and contribute in a technologically rich society." ${ }^{11}$ Based at The Science House, Photonics Leaders program seeks to enhance access to science classes and careers for all students, especially minority students, by giving them opportunities to participate in real scientific investigations making use of a variety of technological tools. The theme of the program, Photonics, is the nexus of optics, electronics, networking, communication and scientific instrumentation. Photonics is the basis of optical communication from the optical fiber of the DVD to the plasma screen. The photonics industry requires hardware and software scientists and engineers who will design, build and maintain the nation's communications infrastructure. Electronic and photonic instrumentation appear in every manufacturing plant and research establishment in the country. 
We have chosen photonics because it allows students to investigate the technology they see and use on a daily basis. They will investigate how the physics of light and the technology of solid-state electronics meet in devices such as TV remote controls, or fiber optics computer connections, or CD players. The Photonics Leaders wire simple devices such as an optoelectronic interface, simulate projects with scientific software, and learn to use a variety of technology tools that make real-world scientific investigation possible. We enhance students' ability to communicate orally and in writing, hone their mathematics skills, and provide them strategies to help them succeed in high school and higher education for STEM careers.

The high school juniors and seniors that participate in the year-round (Fall, Spring and Summer) program for two years

- take part in hands-on science and technology activities to increase their awareness of photonics careers and prepare them for further education and the workplace,

- enhance their mathematics and communications skills and develop career awareness, and

- plan, conduct and report research projects, and serve as interns in research or technology laboratories at NC State or in Research Triangle Park.

Students are recruited from public, private, charter and home schools from across North Carolina but especially in Wake, Johnston, Harnett, Chatham, Orange, Durham and neighboring counties. Most will come from middle school Imhotep Academy and Photonics Xplorers programs at The Science House. The program will also tap into other pre-college programs at NC State (SPACE program) and UNC-Chapel Hill (MSEN pre-college program). This recruiting area includes urban and rural schools. In the past Imhotep Academy students have traveled from as far away as the village of Ahoskie, 3 hours from Raleigh, to participate.

The Photonics Leaders will step into new roles as future scientists and engineers. They are encouraged to develop a mission statement, set goals, develop and prioritize strategies, and accomplish their objectives. Students work in teams on learning assignments and research activities. Speakers from the technology community and field trips to laboratories reinforce these activities. Students develop PowerPoint presentations and web pages to report their research, and use spreadsheets and data analysis software to analyze their results. The juniors and seniors undertake a cooperative research project and explore the world of work through a summer internship. Teachers coming from the research community and The Science House guide high school students in their work.

The Photonics Leaders meet minority scientists from the university and industry who serve as role models for the Xplorers and Imhotep students. We are building a community of minority students and families that encourage academic achievement and success. It has been pointed out that peer culture has a negative effect on the representation of African American students in science. ${ }^{12}$ The Photonics Leaders produces a reinforcing peer culture among the participants and the sister programs of Imhotep Academy and Photonics Xplorers.

Students participate in a three-week summer experience (120 hours) which also includes a field interaction, five Saturdays (4 hours each) in the Fall and five Saturdays (4 hours each) in the Spring, totaling 150 hours per year. The students will receive a scholarship of $\$ 1200$ per year to remove the temptation to take a part-time job else where. To encourage students to remain in the program and to allow them to use technology daily, participants are issued a jumpdrive, an example of a photonic device. Three cohorts of 20 students participate for two years. Because the third cohort students will only complete one year we will seek alternate learning opportunities for their senior year.

Photonics Leaders use teaching strategies and materials from several other high school science programs at The Science House. Much of the format for collaborative research, experimentation and reporting comes from the successful Student Science Colloquies, which introduced students to areas of innovation in science. ${ }^{13}$ Many Colloquies graduates have gone on to university work in science and engineering. Photonics students investigate technology they encounter routinely. Students built telescopes, laser diode circuits, electronic robots, fiber optic light guides and carry out scientific research using lasers and other photonics devices in biweekly and monthly sessions. 
Photonics Leaders served 41 students, 19 males (46\%) and 22(59\%) females in two years from Alamance, Durham, Harnett, Nash, Northampton, Pitt, Onslow, and Wake counties. Students were selected to produce a diverse cohort of students with the following ethnic backgrounds: 77\% African-American, 4\% Asian, 2\% Bi-racial, 14\% Caucasian and $2 \%$ Hispanic. Five students were placed on the waiting list and joined the program before the first session due to attrition. Their unweighted grade point average was a 3.02 .

\section{Evaluation Strategies}

Through pre- and post-student attitude assessment of the students, we measured the impact of the program on the students' perceptions of science and their perception of themselves as scientists or engineers. We regularly survey their parents to learn their perceptions of the program and their understanding of the education choices they and their children must make. We track student's courses and grades through their senior year.

Internal surveys are used to plan the mentoring sessions for parents and students. Sessions on high school preparation, college planning, and strategies for parents to encourage their children to persevere in advanced mathematics and sciences courses in high school were incorporated in the parental component.

After each semester we analyze the curricula and student products to refine plans for the next semester. The learning activities we develop will be reused in other Science House programs and student products will be displayed on The Science House website. Program outcomes and successes are reported through papers and presentations at professional education meetings.

Evaluation Outcome Selections from Photonics Leaders Project 2006-2007 Year Two report EDSTAR, Inc ${ }^{13}$ Goal 1: The first goal of the program is to guide and prepare high school students recruited from minority-serving programs at NC State and elsewhere through and for a transition to STEM programs in two- and four-year colleges.

This goal was evaluated using the following measurable outcomes:

- Evaluation Objective 1.1 Students complete a pre-test at the beginning of the 3-week summer program and a post-test at the end. The post-test is administered again after the five Saturday sessions held in the fall.

- Evaluation Objective 1.2 Students' grades and performance on the state's End-of-Course exams will be collected each fall and spring, and evaluated for all major core curricula (e.g., English, Science, Mathematics, History).

- $\quad$ Evaluation Objective 1.3 Each student's participation in Photonics Leaders will be continuously monitored over two years, as will their selection of courses including the sciences and advanced placement classes. Additionally, $90 \%$ of students will express satisfaction ("satisfied" to "very satisfied") with the program, and will be able to articulate an understanding of possible STEM career paths they could pursue for post-secondary education.

Goal 2: The second goal is to impart to participants a deeper and richer understanding of STEM careers as human endeavors that require hands-on skills, resourcefulness, and communication skills not often addressed in the high school science and mathematics classroom. This goal was evaluated using the following measurable outcomes:

- Evaluation Objective 2.1 Students will maintain a journal where they will record their experiences and observations, and respond to writing prompts periodically (e.g., "Define 'hypothesis' and how one is evaluated." "Describe some of the major steps in conducting a research investigation." "Identify five fields of scientific investigation."). EDSTAR will score the writing prompts using a 4-point rubric (1-showing little to no understanding; 4-showing very good understanding).

- Evaluation Objective 2.2 Each year, students will complete the Test of Science-Related Attitudes, designed to measure secondary students science-related attitudes along seven dimensions: social 
implications of science, normality of scientists, attitude toward scientific inquiry, adoption of scientific attitudes, enjoyment of science lessons, leisure interest in science, and career interest in science.

Evaluation outcomes in science knowledge, writing and science content prompts, student presentation, interest and aspiration are discussed further in this section.

Science knowledge --Content subjects covered included:

- Wave velocity, wavelength and frequency

- Coherence and incoherence

- Differences between an incandescent lamp, an LED, and a laser

- How a lens can be used to magnify an object or expand a light beam

- Differences between sound and light waves

- How the color and wavelength of light are related

- The components of a simple electronic circuit

- How electrical currents are used to produce sound or light waves

\section{Content Tests}

Each student in the Photonics Leaders Program takes a Science Knowledge Content Test designed to help the program staff understand what the students know as they begin the program. The 10-item test consists of 6 openended questions, ( 1 of which also has a multiple choice portion), 3 multiple-choice questions, and 1 diagram. One of the multiple-choice questions asks how the student learned about the Photonics Leaders program. The other questions focus on different aspects of photonics such as light, waves, and electrical circuits.

The final question asks students to draw a picture of what they believe a photonics scientist or engineer looks like at work, including details to show what the scientist's laboratory, activities and lifestyle are like. Each question is scored using a rubric ranging in scores from 1-5 with 5 being the highest. Students are graded on their level of understanding of the concepts mentioned in the content test. With regards to the question in which students are asked to sketch the scientist, the characteristics of the drawing are used to assess students.

In September 2005, 21 participants from Cohort I were given these tests, which the instructors then scored. The average pre-test score was 12.1 of a possible total score of 43 . In December 2005, 17 Cohort I students took the same test and their average score was 16.5 , for an improvement of 4.4 points. Twelve of students' test scores increased and five of the twelve increased by at least 5 points.

In April 2006, 9 students from Cohort I retook the test, scoring an average of 24.4. Between December 2005 and April 2006, the students average test scores increased by 7.9 points. Seven students' test scores increased, and five of the seven increased by at least 5 points. The average score increase over the three testing periods was 12.3 points.

Cohort II students were added to the program in the spring of 2006. They were given the science content test on June 26, 2006 as a pre-test and July 20, 2006 as a post-test. Thirteen students took the pre-test; 12 of these students also took the post-test. The average pre-test score was 12.6 and the average post-test score was 23.8 (of 43). All twelve students increased their test scores—one by as much as 14.4 points.

During Summer 2006, Cohort I took another science content test that would measure prerequisite knowledge of the photonics content they would learn during the summer. This science content test contained 4 multiple-choice questions. The following topics are covered on the test: laser beams and the characteristics of their paths, waves, and electronic circuits. Students received one point for each correct answer for a total possible 4 points.

Cohort I took the second science content assessment as a pre-test on June 26, 2006 and as a post-test on July 20, 2006. Twelve students took the pre-test with an average test score of 2.8 of 4 . Eight of the twelve students took the post-test with an average score of 2.9 of 4 .

The strongest predictors of student content post-test scores were their weighted high school GPAs upon entering the program. The correlation coefficient was .53. 


\section{Writing and Science content prompts}

In addition to the Science Content Assessment, the students are periodically given science-related prompts—small scenarios in which they are required to write how they would react in such a situation. Some are specifically related to the Photonics Leaders curriculum; others are more generally scientific. Students are graded not only for the content of their response, but also for their writing skills. Students receive scores of 0-4 in each of these categories. Students are given 6 prompts a year, three in the fall and three in the spring. After each prompt is scored, a short feedback summary is provided to the director of the Photonics program so that feedback can be provided to the students for continued improvement. Following are examples of prompts given in the fall and spring.

Prompt 1: Cell Phone Prompt

Prompt 2: Telescope Prompt

Prompt 3: Fiber Optic Prompt

Prompt 4: Laser Range Finder Prompt

The writing and content prompt results follow:

\section{Cell phone prompt}

There is a fear that using a cell phone can be damaging to health. Sociologists, economists, scientists and politicians all have opinions on how to respond. If you were a scientist, how would you investigate this issue? Both Cohorts I and II completed the first prompt, and Cohort I have completed it twice-once during their first year and again during their second year. Among Cohort I students, their writing improved tremendously from the first year to the next. In the first year, nine students from Cohort I answered this prompt. Of the seven students who retook the cell phone prompt in Year 2, six improved their scores. None of these students received a 4 in the first year, and only one student received a 3 . When they retook the test, four received a 4 and two received a 3 . Their average writing scores went from 1.8 to 3.1 .

Cohort I science content grades also improved and students took different scientific views of the problem. Some treated the problem as if cell phones were damaging to use while driving because they might cause accidents. Others would examine potentially harmful emissions from the phone itself. Both were legitimate ways to address the prompt. Their science scores improved from an average of 1.1 to 2.0.

Cohort II responded to this prompt during their first year. Although no comparisons can yet be made regarding their own improvement, their writing scores were higher than the first writing scores of Cohort I for the same prompt. Their average writing scores were 3.1; their average science scores were 2.2.

\section{Telescope prompt}

You work for NASA and are in charge of tours for middle school students. One asks you what a telescope is and how it works. How would you respond?

Cohort I responded to this same prompt during Year 1 and during Year 2. Nine students answered this prompt during Year 1, and seven of these nine answered it again in Year 2. Again, writing scores improved dramatically, with only one student receiving a 4 and one student receiving a 3 initially, and four of the seven students receiving scores of 4 during their Year 2 attempt. Average writing scores improved from 2.2 to 3.4.

Five of nine students from Cohort I received scores of 1 for their science content the first time they responded to the prompt. Of the seven who responded again during Year 2, four received scores of 3, and nearly all improved. Average science content scores went from 1.6 to 2.6.

Fifteen students from Cohort II responded to this prompt, and 8 of the 15 received scores of 4 for their writing. The writing score average for all 15 was 3.0. Their average science content score (1.9) was slightly higher than the first Cohort's average. 


\section{Fiber Optic Prompt}

You are a fiber optics expert. Describe several real world applications of fiber optics and its importance to a seventh grade student, friend or parent.

Both Cohorts I and II took this prompt in November 2006 for the first time. Four students from Cohort I and nine students from Cohort II completed this prompt. The three Cohort I students averaged 3.0 for their writing scores and 3.0 for their science content scores. The nine Cohort II students scored higher with averages of 3.8 for both their writing and science content scores.

\section{Laser-Range Finder Prompt}

What is a laser range finder used to measure and describe how you would use this device to carry out an experiment related to applications of photonics in engineering, chemistry or biology?

This prompt was given to Cohorts I and II for the first time in March 2007. Nine Cohort I students and 19 Cohort II students completed this prompt. The Cohort I students averaged 3.3 on their writing scores and 3.1 on their science content scores. Again, the Cohort II students scored higher, averaging 3.6 on their writing and 3.4 and their science content.

\section{Student Presentations}

Students are given a number of opportunities to horn their oral communications skills. They are coached in presentation skills and the development of a professional image, including appropriate attire. The presentations are also an opportunity to demonstrate what they have learned about various topics in photonics.

Students gave brief presentations demonstrating their knowledge and understanding of Photonics for their classmates and instructors. The first presentations were on various topics related to sound. The second presentations were on various topics related to lenses. At the end of the spring semester, and again at the end of the summer program, students gave presentations before an audience of their classmates, instructors, parents, industry and university supporters as well as The Science House staff. The presentations were very well received. Students dressed professionally, and the presentations showed evidence of careful preparation and scientific knowledge. In the spring, students were asked to choose a photonics-related topic to present. Topics were wide-ranging and reflected the students' interests and comprehension of physics concepts as they related to photonics. For the first time, students were required to accompany their talks with a visual aid. The students were also required to prepare a poster for a session following the oral presentations. In many cases, the posters produced did double duty as a visual aid for the presentation, although some students chose to produce PowerPoint presentations. Most students demonstrated excellent speaking skills-appropriate posture, eye contact, volume, etc. Some students found that their visual aids were too small for the audience to see well. Some students also found themselves facing the visual aid instead of the audience.

During the summer, each student built a device that worked based on photonic/optoelectronic principles. One element that stood out was the students' ability to discuss how their finished projects were suppose to work. Students whose projects didn't work were able to articulate hypotheses as to why the devices didn't work. Most were not discouraged, and their problems were often not the result of carelessness, but rather too many things having to go right for the end result to work. Students readily admitted their mistakes, which often included soldering improperly (a skill which takes practice), ambiguous directions (two young men told how the directions instructed them to use a "grown" resistor, and they weren't sure if it meant "green" or "brown"), etc. Many of the "failures" were actually successes, in that the students knew what probably went wrong and how they would do it differently.

They were also able to articulate many scientific properties of their devices. On young man who successfully produced a random number generator told why it was actually more random than throwing dice, and explained the variables involved in the latter. One student who produced a laser mouse with a microphone told how she now understood how her remote control for her television worked. The students who did not produce successful devices seemed to learn as much as those who did.

Seven Cohort I students gave presentations in both the spring 2006 and the summer 2006. Students were graded on a 4.0 scale. Students improved in nearly every area of presentation and delivery, with the most dramatic improvement in the use of visual aids.
"What I learned mostly from the lab is that even if something does not work perfectly, you can still gain something from it.... This has opened me up to do more technology-based things other than just a business type career. I want to do things that are more hands-on now."-a Photonics Leader student presenting her random number generator in which only one die of two 
The presentations were overall a successful element of the program. One could see growth in the students throughout the year. As their presentations became more polished and their scientific knowledge increased, their enthusiasm also became more apparent. The students seemed to be enjoying the program and appreciating the opportunity to learn sophisticated science.

\section{Interests and Aspirations in STEM}

During the 2005-2006 program year, 22 students from Cohort I reported on their career interests. The majority of them $(73 \%)$ reported interests in STEM careers both at the beginning and end of the year. Students' career aspirations did not change during the year.

In fall 2006, both Cohorts I \& II students responded to questions about career interests and intended college majors. Of the 32 students, $20(63 \%)$ listed STEM-related careers such as computer and aerospace engineering and the science of medicine and pharmacology.

\section{Data Summary}

Evaluation outcomes in science content knowledge indicated the average scores of the participants have constantly increased from three to twelve points during each testing. In writing and content prompts Cohort II students are scoring consistently higher in their writing as compared to the scores of Cohort I who's skills have steadily improved over time. Student presentation skills have demonstrated significant improvement over time due to the increase photonics knowledge with ability to organize content, delivery and producing appropriate visual aids and scientific models. Tremendous student growth was noted in this area-from students being unable to speak for 90 seconds to running out of time in a three to five minute presentation. Interest and aspirations reflect the least amount of change due to the majority of the students participating in these programs come highly motivated and dreams of pursuing a degree and or career in the STEM discipline.

At the closing of the Photonics Leaders spring session, twelve of the eighteen parents in attendance shared their perceived impacts of the program:

- $67 \%$ of parents believe that the Photonics Leaders program has helped their child decide on a specific career or college, considering they entered the program with an interest in science, technology, engineering and mathematics

- $50 \%$ of parents believe their child has benefited from the program

- $25 \%$ of students have included NC State in their list of potential colleges.

- $17 \%$ say that their child is more organized.

The Burroughs Wellcome Student Science Enrichment Program Survey (SSEP) shows that $81 \%$ of students who participate in the Photonics programs have a better understanding of a scientist's role, have learned information useful in their science class and are eager to share the Photonics Leaders program with family and friends.

The programs have done a stellar job of targeting minority students. Seventy-five percent of participants are African American, nine percent are Asian/Pacific Islander, 14 percent are Caucasian and two percent are Hispanic. Forty-six percent are male and 54 percent female. Ninety-one percent of the students experienced a successful encounter and have a better understanding of photonics according to BWF SSEP Student Feedback Survey.

\section{Conclusion}

Our complex society of today requires students that can analyze and respond to issues based on an ever-changing knowledge base, which will require students to go beyond memorizing facts by taking initiative and responsibility for their learning. An inquiry-based learning environment provides opportunities for children to do science and learn the problem-solving processes used in communication and thinking skills required for the $21^{\text {st }}$ century.

If North Carolina and the United States wish to remain globally and economically competitive, we must better prepare students and teachers by garnering significant corporate and community support emphasizing the value of science and mathematics. Intervention must occur early to help all children realize that science and technology are a good "fit" for them before something else "hooks" their attention. 
At Imhotep Academy we are committed to empowering a new generation of productive young people and to challenge them to pursue academic excellence and become technologically savvy so they can improve their career choices. Instead of cutting programming we should be expanding our program offerings by

- Leveraging resources from parents, partners, and community leaders to ensure program growth and sustainability.

- $\quad$ Ongoing recruitment of outstanding teachers and students with a passion for science, mathematics and technology.

- Keeping students engaged and motivated through inquiry instruction in all classes from elementary through college.

- Providing opportunities for high school students to mentor other Imhotep students.

- Building parents' awareness of preparing students for a 'flat' world.

- Encouraging high school graduates especially Photonics Leaders to affiliate with the Undergraduate Research Symposium pipeline.

- Incorporating teacher training and developing an evaluation plan for longitudinal documentation of program.

- $\quad$ Publishing the impact of parent, community, university and corporate networks on informal science learning programs at The Science House.

- Incorporating program components to support participants in the program from middle school, high school, college and career and measure the longitudinal impact.

- Developing a seamless curriculum to sustain students through the educational process of becoming future scientists, mentors and technology experts.

- $\quad$ Finding additional grant funding to increase program offerings.

Besides being a multitalented genius, students are reminded that Imhotep means, "to come in peace" and being a part of the global community we must all work together to save our future generation by the choices we make today. This challenges us to scale up the program offerings and makes the program an international model of success for introducing underrepresented students to emerging careers and opportunities in the scientific community and the global workplace.

${ }^{1}$ NC Statistical Profile, NC Department of Public Instruction, http://www.ncpublicschools.org/fbs/stats/

${ }^{2}$ The American Institute of Physics, http://www.aip.org/statistics/trends/highlite/hs2001/figure1.htm, downloaded 10/4/04.

${ }^{3}$ The North Carolina State Testing Results, NC Department of Public Instruction, 2003-2004

${ }_{5}^{4}$ NC Education Directory, 2002-2003, NC Department of Public Instruction

${ }_{5}$ The American Institute of Physics, http://www.aip.org/statistics/trends/highlite/hs2001/figure4.htm, downloaded 10/4/04.

${ }^{6}$ National Science and Program Solicitation NSF 04-611

${ }^{7}$ Cited in Coble and Allen (2005), Keeping America Competitive. Denver, CO: ECS, p.2.

${ }^{8}$ Tapping America's Potential (2005). Washington, DC: Business Roundtable, p.9.

${ }^{9}$ Cited in "Women and Information Technology By the Numbers" (2005). Boulder, CO: NCWIT.

${ }^{10}$ Active Physics, Arthur Eisenkraft, et al., It's About Time Publishing.

${ }^{11}$ EDC, Fall 2006 Newsletter, Issue 3, ITEST Learning Resource Center, a project at Education Development Center. Inc.,under contract \#0323098 from the National Science Foundation.

12"Science Enrichment for African-American Students," R. Miles and J. J. Matkins, The Science Teacher, February 2004, p. 36.

${ }^{13}$ Evaluation Report Photonics Leaders Project Year Two 2006-2007, Mary Bishop Hall, Bernice Campbell, Julie Johnson, EDSTAR, Inc.

Raleigh, NC

${ }^{14}$ Burroughs Wellcome Fund (BWF) Student Science Enrichment Program Survey (SSEP)

http://www.bwfund.org/programs/science_education/program_evaluation 